\title{
Órdenes y beneficios en Palencia
}

\author{
almudena García Herreros
}

\section{Resumen}

Se analiza en primer lugar los diferentes tipos de órdenes sagradas existentes en el seno de la Iglesia, asi como los requisitos para acceder a cada una. $A$ continuación se estudia qué es el

Beneficio, las diferentes clases que habia en la diócesis palentina,

$y$ las características $y$ conocimientos que debian reunir los aspirantes.

Palabras claves: Órdenes, Beneficios.

\section{SUMMARY}

This study analyses the different types of sacred orders within the Church besides the requirements for belonging to each one. Next, we will discover what the Benefit consists of, the different classes existing in the Palencian bishopric and the characteristics and knowledge required in order to be candidates.

Keyword: Orders, benefit.

\section{ORDENACIÓNY ÓRDENES}

En este artículo voy a examinar al colectivo de personas que tenian en común la pertenencia al estamento eclesiástico. Analizaré la jerarquía que conferían las órdenes sagradas y, empezando por los estratos inferiores, continuaré ascendiendo a lo largo de una carrera que habría de concluir en el sacerdocio. Meta que inicialmente todos debían alcanzar, pero que la realidad mostraba una situación bien diferente. Configuraba un colectivo muy heterogéneo, ya que como afirma Dominguez Ortiz «el clero no formaba una clase social propiamente dicha por la varia procedencia de sus miembros, la diferencia en el tenor de vida y la insolidaridad de intereses; pero si una agrupación especial de carácter espiritual y jurisdiccional de difícil definición sociológica» ${ }^{1}$. Este mismo

1 Dominguez ORTIZ, A.: La sociedad española en el siglo XVIII, Madrid, C.S.I.C, 1955, pp. 123 y ss. 
autor ha calculado que el total de clérigos representaba el $2 \%$ de la población total; aunque en términos cuantitativos la proporción era reducida, su peso dentro de la sociedad era mucho mayor por las funciones que desempeñaban y la influencia moral que sus actividades representaban.

El signo de adscripción al ordo clericalis lo marcaba la primera tonsura o corona 2 . Arturo Morgado García la define como «una primera preparación al estado eclesiástico en el que el individuo podía o no perseverar, no había nada en contra para que un tonsurado contrajera matrimonio y llevara una vida completamente seglar» 3 .

Según Gómez Salazar era «una ceremonia instituida por la Iglesia para admitir entre el clero al lego bautizado y confirmado" es decir, aquellas personas que por falta de edad no podían ser ordenadas pero tenían vocación. No la consideraba un orden, sino una preparación para la recepción de las demás, ya que cada una de éstas autorizaba a desempenar unas determinadas funciones, mientras que la simple tonsura no concedía ninguna facultad, limitándose a un rito por el que el laico entraba en el mundo eclesiástico ${ }^{4}$.

Benito Golmayo, sin embargo, la define como "una ceremonia por la cual el Obispo confería solemnemente al candidato el traje eclesiástico, tonsurándole al mismo tiempo, por cuyo acto salia de la clase de los legos, se inscribía en la matrícula de la Iglesia, y principiaba a gozar de los derechos y privilegios clericales de la misma manera que los ordenados de orden sagrado". No concedía ninguna importancia a la discusión de si era un orden o no, para él, el tonsurado podía obtener un beneficio, ejercer la jurisdicción eclesiástica, predicar con licencia del obispo, y ejercer todos los oficios de los ordenados de menores -excepto el de exorcista- 5 . Los futuros tonsurados debían ser cuidadosamente seleccionados, pues era una preparación para recibir las órdenes sagradas, exigiéndoseles que fuesen hijos de legítimo matrimonio.

2 Llamada así porque en dicha ceremonia, uno de los ritos que se realizaba era el corte de cabello como distintivo de la vida clerical a la que se incorporaba, y la corona que se hacía al aspirante en la cabeza recordaba la corona de espinas del Salvador.

3 Morgado García, A., El clero gaditano a fines del Antiguo Régimen, Fundación Municipal de Cultura del Excmo. Ayuntamiento de Cádiz, 1989, pp. 105.

4 Gomez Salazar, F., Instituciones de Derecho Canónico, 3 vol., 3. ${ }^{2}$ ed., Imp. de Herederos de Miñón, León, 1891, pp. 230.

5 Benito Golmayo, P., Instituciones del Derecho Canónico, Madrid, 1885, Sexta edición, Tomo I, pp. 170. 
La línea divisoria entre el mundo secular y el eclesiástico era muy fluida, lo que permitía que un gran número de personas, que habían entrado a formar parte de este estamento, llevaran una vida completamente seglar, pero hicieran uso de las prerrogativas que su condición les ofrecía. Muchos accedian a ella como un medio para disfrutar de las ventajas que ofrecía el estado eclesiástico, mediante la obtención de un beneficio o la inmunidad personal que disfrutaban al no estar sometidos al derecho común. Este colectivo que había recibido la tonsura con el fin de continuar la carrera eclesiástica y que gozaba desde su acceso de un beneficio eclesiástico que le permitía vivir, pero que no desempeñaba tareas pastorales, fue el que recibió la crítica más acerada por parte de los ilustrados. Reprobaban su elevado número frente a la escasez de sacerdotes que ejercian la actividad pastoral, tratando mediante la formación del Plan Beneficial de reducir sus efectivos e integrarles en la vida pastoral.

La ordenación era el rito sagrado por el cual el laico pasaba a ser clérigo, sin embargo, en un sentido estricto la ordenación hacía referencia a la ceremonia por la cual al ordenado se le conferían poderes para desempeñar diversas funciones sagradas. Se dividían en órdenes menores y mayores. Las Ordenes Menores o de Grados, no eran sacramentales y estaban limitadas por encima por el subdiaconado y en sus estratos inferiores por la tonsura. Establecidas desde la Antigüedad cristiana, aunque no fueron instituidas por un decreto general, y por lo tanto no se crearon al mismo tiempo en todos los sitios, ni en el mismo número. Perdieron su razón de ser a medida que los laicos asumieron funciones reservadas en el pasado a los clérigos. Por orden de menor a mayor se distinguían cuatro tipos: Ostiario, Lector, Exorcista y Acólito ${ }^{6}$. Como afirma Candau Chacón su pose-

6 Sus actividades espirituales consistian en: «conferencias de moral», definidas por CANDAU Chacón, M." L., El clero rural de Sevilla en el siglo XVIII, Caja Rural de Sevilla, 1994, pp., 61, como reuniones semanales, en las que, partiendo de cuestiones de Teologia Moral, intentaban un conocimiento práctico de materia eclesiástica y pastoral; asistencia al coro determínados días y comunión mensual. El Ostiario era el encargado de cuidar las puertas del templo, no permitiendo la entrada a determinadas personas hasta la parte de la liturgia en que estaban autorizados, otra de sus funciones era abrirlas y cerrarlas. La misión del Lector, consistía en la conservación y lectura de las Sagradas Escrituras en la Iglesia, con excepción de la Epístola y el Evangelio reservado al subdiácono y diácono respectivamente. El Exorcista se ocupaba de conjurar a los endemoniados para expulsar a los espiritus malignos. Por último los Acólitos fueron instituidos para ayudar a los diáconos y subdiáconos en las celebraciones. El Código de Derecho Canónico de 1983 abolió dos de estos grados, manteniendo bajo el nombre de ministerios, a los Lectores y Acólitos. 
sión les autorizaba al desempeño de determinadas actividades dentro del templo, sin embargo, sólo los ordenados de acólitos desempeñaban alguna tarea relacionada con el grado que ostentaban ${ }^{7}$. En ocasiones, las tareas que debian desempeñar requerían la presencia de otros grupos eclesiásticos, así los exorcistas no podían expulsar a los malos espíritus, necesitándose eclesiásticos de condición superior para su desempeño. De esta forma se fueron vaciando de contenido y asumiendo sus funciones otros clérigos e incluso laicos. Estas órdenes nunca se recibían en solitario y formaban a su vez dos subgrupos, los dos primeros denominados "de primeros", y los siguientes «de últimos» grados, aunque la obtención de estas categorías no tenía una correspondencia con el desempeño de las funciones que les eran propias.

Las Sinodales palentinas fijaron los mínimos requeridos para acceder tanto a la primera tonsura como a las órdenes menores. El Sínodo de D. Álvaro de Mendoza, retomando el canon del celebrado por el obispo D. Luis Cabeza de Vaca en el año 1545, enumeraba de forma detallada los requisitos que debían reunir los aspirantes ${ }^{8}$. Éstos eran mínimos, pues estaba destinado a aquellas personas que tenían vocación pero por falta de edad no podian aun ser ordenadas; además, en una sociedad con un alto índice de analfabetismo el nivel de exigencia no podia ser muy elevado, reduciéndose a saber leer, escribir y poseer unos conocimientos básicos de la Doctrina Cristiana, para los tonsurados; y a los futuros clérigos de menores se les exigía, además, el conocimiento del latín. La edad requerida para su acceso tampoco permitía mayores exigencias y, como ni el Concilio de Trento, ni las Sinodales diocesanas la establecieron, ésta quedó fijada en la costumbre de «el uso de la razón», tanto para la coro-

7 Candau Chacón, M." L., o. c., pp. 60.

8 Mendoza, A. de, Constituciones synodales del obispado de Palencia, copiladas, hechas y ordenadas ahora nuevamente, conforme al Santo Concilio de Trento, Burgos, Philipe de lunta, 1585, Libro I, “De Temporibus ordinandorum», cap. I, pp. 50-51, decía: “Lo que cada clérigo debía sabei quando se viniere a examinar, para ser ordenado de ordenes menores o sacros (...) para la primera Corona, han de estar confirmados, y sabrán perfectamente signarse y santiguarse, y el Credo, y Pater nr. y Ave Maria, y Salve Regina, los Articulos de la fe, los Mandamientos de la ley, y los de la santa madre Yglesia los Peccados mortales, las Obras de misericordia, las Virtudes, los cinco Sentidos, conforme al sumario de la doctrina christiana, destas nuestras constituciones, y sino lo supieren no serán admitidos, hasta que enteramente estén sufficientes en ello: y han de saber bien leer latín, y escribir - Los que se hubieren de ordenar de los quatro menores ordenes, ha de saber todo lo susodicho, y serán examinados, particularmente en cada cosa dello, y han de construyr, alomenos una oración, de manera que se entienda, tienen alguna inteligencia de la lengua Latina”. 
na como para las órdenes menores, ya que ambas podían ser recibidas en una sola ceremonia.

Los subdiáconos, diáconos y presbíteros conformaban las llamadas Ordenes Mayores, es decir, los cargos propiamente dichos de la carrera sacerdotal, eran los clérigos ordenados in sacris, su estado implicaba la realización del voto de castidad, y el derecho de acercamiento físico a los vasos sagrados. Se les conocía también como orden Epístola, Evangelio y Presbiterial o de Misa respectivamente 9 . El Sínodo de D. Álvaro de Mendoza de nuevo detalla la ciencia que debían poseer los aspirantes ${ }^{10}$. La edad requerida para acceder a cada una de los órdenes era la misma que marcaba el Concilio, haber cumplido 21 años para ser subdiácono, 22 para diácono y 24 para disfrutar de un beneficio de preste. De las tres categorías ésta era la única que permitía desarrollar funciones propias de sacerdote. El Concilio deseaba que los futuros sacerdotes tuvieran una amplia formación con conocimientos de gramática latina, canto..., al tiempo que se exigía a los estudiantes la memorización de las Sagradas Escrituras, libros eclesiásticos, homilías de los Santos y fórmulas de administración de los Sacramentos 11.

9 El subdiaconado en un principio no fue un orden sagrado, la elevación a esta categoría la realizó, mediante decreto, el papa Urbano II en el siglo XI.- BENITO GoLmaYo, P., o. c., I, pp.163 y ss., consideraba el diaconato como el orden preparatorio para el estado sacerdotal, debiendo permanecer únicamente el tiempo indispensable de prueba establecido por las leyes eclesiásticas, sin embargo, muchos diáconos permanecieron en este estado sin pasar al orden presbiterial, por último definía a los presbíteros como «sacerdotes de segundo orden, los cuales bajo la dependencia del Obispo, desempeñan en la iglesia varias funciones del ministerio eclesiástico. Forman el segundo grado de la jerarquía de derecho divino (...), y se les denomina también sacerdotes à sacris faciendis".

10 MendozA, o. c., pp. 51, «Los que han de recibir la orden de Sudiacono, ha de saber lo sobredicho, (esto comprendia recordar todo lo exigido para conseguir la primera tonsura y las ordenes menores, ver nota a pie de pág. $n .{ }^{\circ} 8$ ), y ser assimismo examinados en ello y han de tener sufficiencia por lo menos en leer y en latinidad, $y$ en cantar $y$ en saber rezar, y regir el brebiario nuevo. -Los que han de recibir la orden de Diacono, han de tener suficiencia en lo sobredicho. -Los que se hubieren de ordenar de Missa, han de tener sufficiencia en todo quanto esta dicho, y en saber y entender los Sacramentos, y de las demás cosas pertenecientes a su orden, y las ceremonias de la Missa, conforme al nuevo Missal Romano; y sin estar bien instruydos en ellas no se les ha de dar licencia para dezilla; y porque en esta santa orden se recibe poder de absolver, teniendo licencia de su ordinario, o en caso de necesidad urgente, han de saber los ordenados de Missa, la forma de absolucion de peccados, y qualquiera excomunion, para que acierten a hacer lo que tanto importa. $-Y$ mandamos a nuestros examinadores sea en todo lo sobredicho muy vigilantes, y no aprueven a ninguno sin la dicha sufficiencia, y en guarden puntualmente esta instrucción".

11 Candau Chacón, M.² L., o. c., pp. 176. 
Las obligaciones espirituales que debían realizar los ordenados de mayores en su condición de eclesiásticos, consistían, sobre todo, en la realización de diferentes actos litúrgicos, como la celebración del Oficio Divino o la recitación de las Horas Canónicas ${ }^{12}$, la asistencia a celebraciones de solemnidad en determinados días y por último, los presbíteros administrar los sacramentos. Con los ordenados de menores compartían otras actividades, como las conferencias morales semanales, una mayor práctica espiritual y la recepción periódica de los sacramentos. EI Sínodo de D. Álvaro de Mendoza relata las tareas que a cada ordenado le tocaba desempeñar dentro de la Iglesia ${ }^{13}$.

Como acabamos de ver, desde la recepción de la primera tonsura hasta el presbiterado, el clérigo debía recorrer todo un camino cargado de simbolismo ${ }^{14}$. Escalaba, paso a paso, los diferentes peldaños de la ca-

12 En ellas se reproducian, a lo largo del día y a través de diferentes rezos, la Pasión, muerte y Resurrección de Cristo. En maitines se recordaba la oración en el Huerto, en prima se reproducian las ofensas ante Caifás, la sentencia de muerte la rememoraban en tercia, la crucifixión se revivía en sexta, en nona evocaban cómo fue traspasado por una lanza, por último vísperas y completas cerraban el cuadro de la Pasión, recordando la bajada de la cruz, y la colocación del cuerpo de Cristo en la sepultura.

13 MendozA, o. c., pp. 73-74, "Los que son ordenados de menores tienen officio de tañer las campanas, y de cerrar, abrir y guardar las puertas de la yglesia, y de cantar los Pfalmos, y encender las lámparas a las horas convenientes, y ministrar a los Rectores y Curas en sus officios, quando administren los Santos Sacramentos, y ha de hazer los otros servicios y officios a sus ordenes, pertenecientes y acostumbrados en este Obispado: y siendo a cargo de alguno de los graderos el officio de Sacristán, sera obligado a hazer, assi mismo quanto al tal officio convenga. -El officio y cargo de los Subdiaconos es leer las Epistolas, lavar los corporales con sus manos propias, en la pila del baptizar, traer el Caliz y Hostias al Altar, y ministrar vino, y agua al sacerdote que celebrare. -Ei officio de Diacono es leer el Evangelio y ministrar en el Altar, quado el preste celebrare la Missa. -El officio del Presbytero, es catar y celebrar Missas, y quando el Cura fuere impedido, y fuere por el encomendado, es obligado a administrar todos los Sacramentos, que ocurieren en tiempo del tal impedimento. -Estos officios y cargo tienen los sobredichos cada uno según su orden, y mas todos los otros, que son estatuydos por los santos padres y usados por la costumbre de la yglesiam.

14 Candan Chacón, M." L., o.c, pp. 60, afirma que el clárigo desde la primera tonsura hasta el presbiterado recorría todo un mundo metafórico y ritual que trataba de apartarle del mundo exterior, cada ceremonia realizada para la recepción de los diferentes ordenes, e incluso las palabras pronunciadas, así lo atestiguaban: - "Obra como has de dar cuenta a Dios de las cosas que se encierran bajo estas llaves" (Ostiario); - "Recibe la potestad y sé el relator de las palabras de Dios" (Lectorado); - «Recibe... y ten la potestad de imponer las manos sobre los energúmenos, ya sean bautizados, ya sean catecúmenos" (Exorcistado); - "Toma el cirial con su vela, y sábete que estás destinado para encender las luces de la iglesia, en el nombre del Señor" y "Recibe las vinajeras para suministrar el vino y el agua para la Eucaristía de la Sangre de Cristo, en el nombre del Señorm (Acolitado); -«Recibe el libro de las Epístolas y ten la potestad de leerlas en La Iglesia de 
rrera eclesiástica, primera tonsura, órdenes de menores, órdenes de mayores y como culminación al proceso sacerdotal, el episcopado.

\section{EL BENEFICIO}

Común a todos ellos era la posesión de un beneficio, y se entendía por Beneficio «la renta unida a un oficio eclesiástico, o cargo u oficio en la Iglesia, constituido con autoridad del obispo y dotado con cierta rentas 15 , constaba de un oficio sagrado y del derecho a percibir las rentas anejas a dicho oficio. Se establecía aquí una controversia entre canonistas y teólogos; en los primeros, lo primordial era la potestad en el disfrute de unas rentas, y accesorio el derecho a desempeñar un cargo eclesiástico; mientras que los teólogos consideraban que lo importante no era la percepción de las rentas, necesarias para el titular, sino el desempeño del oficio sagrado. Para Pedro Benito Golmayo no era relevante la primacía de un término sobre otro, pues ambos eran esenciales e inseparables; sin embargo, le parecia más ajustada a la realidad la acepción de los teólogos, ya que podría darse el caso de un beneficio que no tuviese renta y se mantuviera de su trabajo o de la caridad pública, pero no se podría concebir un beneficio con renta pero sin un ministerio que desempeñar ${ }^{16}$.

Los ingresos percibidos por el desempeño del oficio eclesiástico son los que se conocían como prebenda, ésta podría definirse como la dotación económica del beneficio. Su patrimonio estaba constituido por bienes raíces, prestaciones de alguna familia o persona moral, ofrendas entregadas por los fieles y por los llamados derechos de estola, es decir, el arancel o la costumbre que se aplicaba por administrar los sacramentos.

La constitución de un beneficio precisaba el cumplimiento de unos requisitos. En primer lugar era la perpetuidad, el beneficio se mantenía inclu-

Dios, tanto a favor de los vivos, como de los difuntos, en el nombre del Padre, del Hijo y del Espíritu Santo" (Subdiaconado); - "Recibe la potestad de leer el Evangelio en la Iglesia de Dios" (Diaconado); - «Recibe la potestad de ofrecer el sacrificio a Dios y de celebrar Misas tanto por los vivos como por los difuntos, en el nombre de Dios" y «Recibe el Espíritu Santo; a quiénes perdonéis los pecados les serán perdonados, a quienes se los retengáis, les serán retenidos" (Presbiterado).

15 Martinez AlCubILLA, M., Diccionario de la Administración española. Compilación de la Novísima Legislación de España peninsular y ultramarina en todas las ramas de la Administración Pública. Madrid, 1886. 4." Ed., Tomo I, pp. 1056-1057.

16 Benito Golmayo, P., o. c., II, pp. 151. 
so después del fallecimiento del titular, quedando asegurada la permanencia con el nombramiento de uno nuevo ${ }^{17}$. La segunda condición que debía reunir el beneficio era la erección canónica, es decir, que fuese erigido por la autoridad eclesiástica, en la diócesis era el obispo, o que fuese aprobado con posterioridad por él. La falta de esta premisa anulaba la condición de beneficio, convirtiendo lo fundado en una institución piadosa o en un legado pío, pero nunca en un beneficio, aun cuando entre sus obligaciones se incluyesen servicios espirituales o celebraciones de misas ${ }^{18}$. En definitiva no se podía crear ningún bien espiritual ni lugar sagrado sin la autoridad del obispo. Este requisito implicaba dos condiciones, en primer lugar se establecía que era la autoridad eclesiástica la encargada de conceder el beneficio, pretendiendo evitar que este derecho pudiera ostentarle algún laico ${ }^{19}$, y únicamente se podía conceder a eclesiásticos, personas que al menos hubiesen recibido la primera tonsura, se sentaba así una prioridad, primero se recibia la orden y después el beneficio 20 Por último el beneficio siempre llevaba anejo la realización de un oficio sagrado, como la recitación de la Horas Canónicas o la celebración de la Eucaristia, cualquier renta eclesiástica que disfrutase un clérigo si no iba acompañada de unas obligaciones espirituales no era un beneficio.

Existían numerosos tipos de beneficios dependiendo de los criterios de clasificación 21 Aquí analizaremos los diferentes beneficios parroquia-

17 La ley 5, tít. 12, libro I de la Novísima Recopilación de las leyes de España, 6 vols., Madrid, 1805, decretó el cumplimiento de lo establecido en el art. $6 .^{\circ}$ del Concordato de 1737, sobre la perpetuidad de los beneficios, en dicho art. se prohibía a los Obispos la creación de beneficios temporales, quedando abolidos igualmente los que tuvieran esa característica.

18 El legado pío era una fundación perpetua, en la que el testador destinaba parte de sus rentas o bienes a una obra de piedad o beneficencia. Era un término muy amplio que abarcaba numerosas fundaciones.

19 Ello no invalidaba el derecho que algunos patronos tenian, en nuestra diócesis de nombrar clérigos idóneos para el cargo, pues estas personas nombradas debian recibir la colación canónica, es decir, la aprobación por parte del Obispo.

20 Hubo excepciones a esta regla, dándose casos de personas que mediante dispensas recibieron primero la prebenda, sin estar ordenados pero fue con la condición de ingresar en el estado eclesiástico, lo que implicaba simplemente un retraso en la recepción de las órdenes.

$2 \uparrow$ Benito Golmayo, P., o. c., II, pp. 153-ss., distingue los siguientes tipos: Beneficios mayores y menores, los primeros van destinados a los primeros grados de la jerarquía eclesiástica con cura de almas y jurisdicción sagrada, como Pontífices, Patriarcas, Arzobispos, Obispos y Abades; llamados también Beneficios Consistoriales, pues les concedía el Romano Pontífice en Consistorio. Los menores serían todos los demás. -Beneficios Seculares y Regulares, los primeros versaban acerca del régimen y servicio de la Iglesia, y los segundos tenían por objeto la observancia de la disciplina monástica y gobierno de los monjes, como abadlas prioratos y demás oficios claustrales. -Beneficios Curados y Simples, los curados llevaban aneja la cura 
les existentes en la diócesis palentina. En la documentación manejada les hemos encontrado reunidos en tres grupos: Beneficios Simples, Beneficios Patrimoniales y Beneficios Curados.

En la base de los oficios y prebendas se encontraban las capellanías definidas por Alvarez, como «fundación perpetua hecha con la obligación aneja de cierto número de misas $u$ otras cargas espirituales en Iglesia determinada, que debe cumplir el obtentor en la forma y lugar prescritos por el instituyente» 22. Se dividían en dos grandes grupos: Capellanías Colativas o Eclesiásticas y Laicales, las primeras eran auténticos beneficios eclesiásticos, mientras que en las segundas no intervenía la autoridad del obispo, aun cuando tenía el derecho y el deber de hacer cumplir las cargas espirituales impuestas por el fundador ${ }^{23}$. Aquí analizaremos solamente las primeras.

Se las conocía también con el nombre de beneficios impropios, pues aunque su origen se debía a una fundación particular o institucional debía ser erigida por la autoridad diocesana. Podían ser fundadas y vinculadas a cualquier Iglesia o centro religioso, ya fuera de carácter exclusivamente religioso o con fines asistenciales. Así encontramos capellanías sitas en iglesias, oratorios, capillas, ermitas, hospitales... Desde su fundación, la capellanía disponía de unos bienes, desgajados de los del fundador, siendo éstos la dotación económica de la propia capellanía. Dichas propiedades quedaban, en ese mismo acto, vinculadas a la Iglesia y por lo tanto sometidas a su jurisdicción, lo que tenía un doble efecto, en primer lugar estaban exentas del pago de tributos civiles, pero la aplicación de estos bienes al mantenimiento de la capellanía no aseguraba el cumplimiento perpetuo de los fines de la fundación. Si la renta obtenida disminuia o incluso se extinguía con el paso del tiempo, no se podrían cumplir los fines

de almas, requisito que no era necesario cumplir en los simples. -Les habia Aislados y otros que formaban Cabildo. -Otros eran Beneficios Residenciales y no Residenciales. -Por último nos encontramos con Beneficios Patrimoniales, cuya posesión se reservaba a los naturales de un pueblo, provincia y diócesis, eran abundantes en el centro y norte de la península, entre los que estaba incluida la diócesis palentina. Estuvieron vigentes hasta que el artículo 6 del Concordato de 1851 los suprimió.

22 Álvarez y Gómez, M., Manual de capellanias y pías memorias, Vitoria, 1903, pp. 2.

23 Álvarez y Gómez, M., Apéndice al manual de Capellanías y pías memorias, Vitoria, 1919, pp. 11, considera las capellanías laicales «como simples vinculaciones o gravámenes particulares, cuyo instituyente podía imponer todas las condiciones compatibles con las reglas canónicas y con el espíritu de la institución". Únicamente estaban sometidas al Obispo en su aspecto religioso, pero los bienes con que se fundaban no dependian de la autoridad eclesiástica sino de la civil, por lo que no estaban amortizados. 
para los que fueron fundadas, de aquí que fuese de capital importancia una buena administración. Encontramos ya una primera diferencia con los beneficios eclesiásticos, y es que los ingresos de éstos al proceder de diezmos, oblaciones y estipendios de misas, podian variar de un año a otro, pero nunca extinguirse.

Para la obtención de una capellanía colativa solamente se requería estar tonsurado, por lo que al no haber recibido órdenes sagradas podía abandonar el estado eclesiástico en cualquier momento. Esto es lo que pasó en la villa de Guaza a fines del siglo XVIII, cuando el 7 de abril de 1793 fue elegido D. Juan Camino Mayoral, para cubrir la vacante de una capellanía en la mencionada villa; desempeñó las funciones de capellán durante seis años, hasta el 25 de mayo de 1799, fecha en que contrajo matrimonio, y hubo que nombrar un sustituto 24 . La provisión correspondia a los patronos respectivos, y mediante un documento, público o privado, nombraban al candidato. Éste debía presentarse ante el ordinario para solicitar la institución canónica y una vez obtenida el nominado tomaba posesión de la capellanía respectiva y comenzaba a disfrutar de sus rentas.

Sus obligaciones dependian de lo establecido en la fundación. Sin tareas pastorales, sus deberes oscilaban desde la asistencia a las procesiones del Santísimo, a la enseñanza del solfeo o canto liano a los mozos del coro, pasando por los rezos y oraciones que su condición les imponía, como el Oficio Divino. La mayoría exigía la celebración de determinadas misas por el aima del fundador y su familia. En estos casos, si el capellán no era presbítero, debía encargar su celebración a una persona idónea hasta que se ordenase in sacris. En numerosas ocasiones éste era el único recurso del que disponian los capellanes para conseguir la ordenación eclesiástica, sin embargo, no siempre se utilizó con estos fines. Por ello, algunos fundadores erigieron capellanías con el ánimo de incrementar el número de clérigos en el pueblo y establecían que los nuevos capellanes, preferentemente de la familia, dispusieran de la capellanía como un medio para financiar sus estudios, obligándoles en un plazo determinado a ordenarse, si transcurrido este tiempo no lo habian hecho la capellanía quedaría vacante.

Se desconoce su origen, sus antecedentes se encuentran en las mandas y legados que los patronos laicos hacían en favor de alguna iglesia, para sufragios de los difuntos. Se desarrollaron al calor de la desmedida preocupación por la muerte y la creencia en el purgatorio, las capellanias

24 Herreros Estébanez, F., Historia de Guaza, Palencia, 1989, pp. 251-252. 
en este momento llegaron a ser como una "compra" de la gloria eterna. Del siglo XVI al XVIII fue el momento de su máxima expansión, al tiempo que se inicia su decadencia. Los gobiernos ilustrados se dieron cuenta de las repercusiones negativas que tenía la vinculación, y por lo tanto amortización, de bienes raices en manos de la Iglesia. Las primeras medidas limitando la fundación de capellanías se llevaron a cabo en la época de Carlos IV, cuando en 1795, se impuso una exacción del 15 por 100 sobre todos los bienes con que se dotasen; y la prohibición, en 1796, de erigir sin licencia real fundaciones pías perpetuas y capellanías. Dos años más tarde invitó a los obispos a enajenar las colativas y otras fundaciones eclesiásticas, y poner su producto en la Caja de la Amortización, como contribución de la Iglesia al saneamiento de la deuda pública 25.

Debieron ser las piezas eclesiásticas más abundantes pues su ejercicio era compatible con el usufructo o posesión de otro tipo de prebendas. Asi había eclesiásticos poseedores de prebendas de mayor valor, como beneficiados, curas o clérigos capitulares, que en atención a su mayor graduación no eran denominados capellanes, sin embargo, desempeñaron las tareas que la capellanía imponía. Desde el simple tonsurado hasta el presbítero todos podian ser capellanes. En la diócesis de Palencia el obispo Argüelles decía que no eran objeto del presente estudio (haciendo alusión a la reforma beneficial), y que de «su unión y agregación se tratará cuando se haga el correspondiente a Capellanias" dicho Plan no llegó a realizarse ${ }^{26}$. Aunque desconocemos su número y las rentas que poseían es preciso contar con su existencia, pues algunas sirvieron por medio de su unión o supresión para aumentar la dotación de beneficios y curatos. En la iglesia de Belén, en Carrión de los Condes, Arciprestazgo del mismo nombre, de las ocho Capellanias existentes, una estaba aneja al curato, como aumento de congrua, con una renta de 304 reales al año. Según una relación de piezas eclesiásticas que remitieron los pueblos del Arciprestazgo de Población de Campos en 1769 al obispado, en las 19 localidades habia fundadas 58 capellanias 27 .

25 Libro 1, tít. 5, leyes 18 y 22; tít.12, ley 6 de la Novísima Recopilación.

26 «Expediente General. Sobre erección y dotación de curatos propios perpetuos y colativos en todas las Iglesias del Obispado de Palencia. Pieza C", A.H.N., Consejos, leg. 16.052.

27 “Arciprestazgo de Población. 1769", A.D.P., Clero Secular, leg. 3, Exp. 3. A esta cifra habría que añadir 3 Patronatos de Legos, (que con anterioridad habian sido capellanías), definidos por BaraIo Gozalo, M., Estudio socio-económico de la Iglesia de Segovia en el siglo XVIII, Publicaciones de la Caja de Ahorros de Segovia, 1982, pp 489, como "las mismas capellanias laicales y, a veces los simples aniversarios y memorias de misas, llamados así porque los poseedores eran legos y se consideraban como patronos con derecho a nombrar cumplidores de misas o mandarlas celebrar a cualquier sacerdote sin necesidad de nombramiento". 
En la iglesia de S. Martín en Frómista -Arciprestazgo de Población de Campos- ante la falta de Beneficios la erección del vicario se hizo con la fusión de dos capellanías que rentaban 982 reales al año 28 .

\subsection{Beneficios simples}

Su origen se remonta a los primeros siglos del cristianismo, momento en que el obispo como administrador único de todos los bienes de la iglesia, cedió parte de las rentas de la misma a algún clérigo como reconocimiento a labor desempañada, y de las que disponía el usufructo vitalicio. Su configuración jurídica se produjo durante los siglos XI-XII, y se mantuvo hasta fines del siglo XVIII, principios del XIX, momento en que con la reforma beneficial se unieron a otras piezas eclesiásticas o se suprimieron, destinando sus ingresos a diferentes fines piadosos.

Los beneficios simples no comportaban ninguna administración, gobierno o jurisdicción. No tenían cargo de cura de almas, ni obligaciones pastorales, por lo que las responsabilidades eran mínimas, pudiéndose limitar a declamaciones y cantos en el coro, asistencias procesionales, plegarias privadas y poco más. No exigían residencia personal del beneficiado, y los requisitos para acceder se limitaban a haber recibido la primera tonsura y tener cumplidos 14 años 29 . Esto nos hace retomar la idea expuesta más arriba sobre la dudosa vocación de dicho colectivo, en muchos casos serían segundones de alguna familia hidalga que eligieron este camino, como salida a su situación personal; otros serían hombres de origen modesto y sin grandes aspiraciones que veían en estos beneficios un medio de asegurarse una vida apacible, también se dio el caso de clérigos que combinaban los exiguos ingresos de su beneficio con otros más o menos compatibles con su actividad.

Estos beneficios instituidos en un principio para el culto divino, con el tiempo perdieron la finalidad para la que fueron creados, convirtiéndose

28 «Expediente General. Sobre erección y dotación de curatos propios perpetuos y colativos en todas las Iglesias del Obispado de Palencia. Pieza C», A.H.N., Consejos, Leg. 16.052, y «Arciprestazgo de Población. 1769" A.D.P., Clero Secular, Leg. 3, Exp. 3.

29 B.arRio Gozalo, M., o. c., pp. 449, nota a pie de pág. n. ${ }^{8} 11$, citando a N. García: Tractatus de Beneficiis, II, séptima pars, cap. IV, afirma que “el derecho antiguo solamente exigía para obtener un beneficio simple la edad de siete años; sin embargo, el Concilio de Trento, en la sesión 23, capítulo sexto, decretó que ninguno pudiera obtener un beneficio eclesiástico antes de estar tonsurado y tener cumplidos los catorce años". Las sinodales palentinas no especificaron nada con lo pensamos que acataban las normas tridentinas. 
en simples beneficios sin oficio (de aquí su nombre). En cuanto a los beneficios simples con que contaba el Obispado de Palencia, sabemos de su número por diferentes relaciones que enviaron los prelados palentinos en contestación a los encargos de la Cámara, para conocer los beneficios incongruos que había en las respectivas diócesis. Ch. Hermann ofrece, para 68 parroquias en el último tercio del siglo XVIII (pero sin concretar fecha), la cifra de 286, entre Beneficios Simples y Capellanías ${ }^{30}$. En el Anteproyecto de Reforma Beneficial que envió a la Cámara el obispo Bustamante, informaba que en 1752 había 131 beneficios simples cuya renta ascendía a 24 ducados de oro. En 1760 hablaba ya solamente de 97 beneficios, y proponía la supresión de todos debido a la escasez de sus rentas y a que no eran de ninguna utilidad para la iglesia ${ }^{31}$.

Los diferentes prelados solicitaron a los Arciprestes relación de los beneficios vacantes. Con la que solicitó el obispo Mollinedo se elaboró una lista detallando los beneficios existentes en 1781, en ella podemos comprobar que habia 41 beneficios simples sin titular 32 . Algunos llevaban más de 30 años, concretamente en la localidad de Antigüedad (Arciprestazgo de Baltanás), había dos beneficios simples vacantes, uno desde abril de 1749 , intitulado de Penedillo ${ }^{33}$, y el otro llamado de Villella sin beneficiado desde agosto de $1753^{34}$. La mayoría vacaron en la década de los 70 , pero debido a la escasez de sus rentas quedaron sin proveerse, ya que los ingresos medios no alcanzaban los 800 reales al año, aunque esta cifra ocultaba importantes variaciones como los 1.744 reales. de un beneficio en Tordehumos, 0 los 70 reales de uno en Astudillo, o los 150 de otro en Villarmentero. Los titulares eran muy variados, pues al no exigir residencia, el poseedor podía ser

30 Hemann, Ch., L'Eglise d'Espagne sous le patronage royal (1476-1834). Essai d'eclesiologie politique. Casa de Velázquez, 3. Madrid, 1988, pp. 250.

31 «Expediente respectivo a Planes Beneficiales de la Diócesis de Palencia. Pieza G", A.H.N., Consejos, leg. 16.052 .

32 De los 41, 3 se localizaban en el Arciprestazgo de Avia de las Torres, 5 en el de Astudillo, 4 en el de Baltanás, 1 en el de Becerril de Campos, 3 en el de Carrión de los Condes, 1 en el de Castromocho, 2 en el de Cevico la Torre, 3 en el de Herrera de Pisuerga, 1 en el de la Ojeda, 1 en el Ordejón con Redondo, 4 en el de Peñafiel, 3 en el de Población de Campos, 1 en el de Rioseco, 5 en el de Tordehumos, 3 en el de Torrelobatón y 1 en el de Urueña.

33 Tenía la particularidad de denominarse en los años pares "Préstamo", por lo que la catedral adquiría el derecho a percibir la décima parte de los ingresos que se produjeran en dichos años. Estos eran muy exiguos, pues se limitaban en el año común del quinquenio 1776-1780, a: 8 cargas y 6 quartos de trigo; $3 \mathrm{cg}$., 2 celemines y 2 quartillos de cebada; $1 \mathrm{cg}$., 1 q., 4 c. y 3 quartillos. de avena y por último 23 rs. 16 mrs. en concepto de diezmos de cordero.

34 Este beneficio era en los años nones en los que se consideraba "Préstamo", y por lo tanto el titular no recibía nada, siendo la catedral la destinataria de dichas rentas. 
miembro de la comunidad eclesiástica donde radicase el beneficio, o estar en un lugar apartado. Así encontramos como titulares de beneficios simples en el obispado de Palencia, a un presbítero de la villa de Lumbroso en el obispado de León, otro residente en Madrid, un clérigo de menores del obispado de Valladolid, un racionero de la catedral de Ávila, otro de la catedral de Valladolid o un canónigo de la catedral de Palencia.

En 1784, el Consejo de Castilla solicitó a todos los Prelados del reino la elaboración de unas listas en las que enumerasen los Beneficios Simples vacantes que había en cada Obispado, con las rentas que disponían, las cargas que soportaban y la calidad. El obispo Mollinedo la confeccionó pero sólo dio cuenta del lugar donde se encontraban el Beneficio vacante, el año que se produjo y la renta que poseía. La renta media calculada para estos 46 Beneficios era de 576 reales al año, sin embargo, esta cifra podría dar lugar a error, pues eran cargos que englobaban a todo el Obispado y junto a algunos que superaban los 1.000 reales de vellón anuales, como los de Autilla del Pino, Báscones de la Ojeda o Becerril de Campos, habia otros que no llegaban a los 100 reales al año. En esta situación se encontraban cuatro: un Beneficio en Avia de las Torres vacante desde el 13-7-1779, con una renta anual de 77 reales; dos en Astudillo, vacante el primero desde finales de los años 70 que disponía de 78 reales, y el segundo sin adjudicar desde finales de la década de los 60 que gozaba de 90 reales; por último el cuarto estaba libre en Tordehumos desde el 7-12-1774 con 88 reales 35 .

\subsection{Beneficios patrimoniales}

Se llamaban así porque únicamente se concedian a los naturales del pueblo, diócesis o provincia, Palencia era una diócesis regida enteramente por una patrimonialidad local 36 . Este era un privilegio ratificado en 1502, por Bula Apostólica del papa Alejandro VI, a instancia de los Reyes

35 «Expediente general de uniones y supresiones de Beneficios del Obispado de Palencia. Pieza A", A.H.N., Consejos, leg. 16.052.

36 Garcia Garcia, A. Synodicon Hispanum, Tomo VII, B.A.C., Madrid, 1997, pp. 479, reproduce lo establecido en el sinodo de 1500 del obispo Diego de Deza, sobre a quien se podía considerar patrimonial, «se entiende hijo patrimonial de aquella iglesia en la cual el padre o la madre o el abuelo o la abuela fue natural e parrochiano" ... «Salvo si por ventura, mudado el domicilio por el padre o madre o por el abuelo o abuela antes que el hijo patrimonial sea ordenado de orden sacro, en otra parte estuviere por diez años con animo de permanecer alli, o despues dellos muertos cumpliere los diez años; en tal caso pueda ser promovido a ordenes menores e sacros a titulo de la iglesia del segundo domicilio y conseguir alli beneficio patrimonial». 
Católicos; asi lo afirmaba el obispo Argüelles en 1775 en contestación a la carta orden de la Cámara fechada el 11-8-1772, en la que solicitaba información sobre la forma de proveerse los beneficios patrimoniales ${ }^{37}$.

Estos beneficios asumian las cargas de la iglesia y las responsabilidades pastorales, incluía a todos los que habian recibido órdenes sagradas y estaba formado por tres categorías (establecidas por Trento y llamadas Ordenes Mayores), presbiteriales o beneficio de preste, diaconales o beneficio de evangelio y subdiaconales o beneficio de epístola. Tras la Reforma todos los beneficios serán presbiteriales ${ }^{38}$. Eran de obligada residencia e incompatibles entre sí, o con cualquier otro cargo que también exigiese residencia ${ }^{39}$. Estaban obligados, en el plazo de un año, a

37 Según el prelado «de tiempo immemorial se havia obserbado la costumbre de probeer los Beneficios de este obispado entre los hijos Patrimoniales de sus respectivos Pueblos, confiriendolos al mas digno moribus et scientia, et interpares antiquori. Suplicaron a Su Santidad se dignase dispensar la gracia de que se obserbase la practica de dicha costumbre, reserbandolos de la regla de cancelari. Su Santidad condescendió a la suplica expidiendo Bula para que se procediese a la provision en los Beneficios en el modo, y forma, que hasta allí se havia observado, iusta laubabiles connsuetudionis, et statuta sinodalia de este obispado como consta de su contexto", "Expediente promovido a instancia del Sr. Fiscal (...) sobre la provisión de Beneficios de este Obispado. Año 1758 a 1808», A.H.N., Consejos, leg. 16.052.

38 En este grupo también estaban incluidos los beneficios de grados, concedidos a los clérigos que habían recibido alguna de las 4 órdenes menores, llamados graderos por esta causa. Para obtenerlo era necesario tener cumplidos 14 años. En algunas ocasiones se les denominaba con el nombre de la función que desempeñaban, asi nos encontramos, por ejemplo con beneficio sacristía, haciendo alusión a la tarea propiamente dicha. Después de la Reforma esta labor la desempeñarán legos retribuidos por el párroco. Los graderos, como grado previo al sacerdocio, no lo eran simplemente por un tiempo, ni tenían porqué serlo a perpetuidad desempeñando los mismos trabajos que los antiguos clérigos de menores. Era más bien un beneficio que llevaba esa graduación y de ordinario los simples graderos celebraban también misa, así como los beneficiados de epístola y evangelio.

39 Todo el tít. 15, libro l, de la Novísima Recopilación está dedicado a la residencia de los beneficiados. Las Constituciones Sinodales promulgadas por los diferentes prelados hacian igualmente alusión a este tema, así en las de MENDOzA, O. c., en el libro l «De aetate \& qualitate \& ordine perficiendorum", pp. 55-56, dice que la persona que sea patrimonial en varios pueblos y posea un beneficio en uno de ellos no puede aspirar a otro si no hace renuncia previa al que ostenta. En el libro III "De clericis non residentibus", pp. 137 y ss. detallaba de forma pormenorizada las circunstancias por las cuales podia ausentarse un beneficiado de su cargo, modo de cubrir esta vacante, así como las situaciones en que por ausencia continuada se perdía el beneficio. En el mismo libro III, cap. XVII «De Praevendis», pp. 157, retoma la idea expuesta en el Sínodo de Luis Cabeza de Vaca de 1548, sobre la prohibición de poseer dos beneficios patrimoniales, aunque fuese en otro obispado "por la continua residencia que cada uno dellos requiere". Esta misma idea aparece en Molino Navarrete, J., Constituciones añadidas a las synodales del obispado de Palencia, Madrid, Antonio Gonçález, 1681, en el título XIII «De Beneficijs \& Beneficiatis, pp. 51. 
ordenarse de la orden que el beneficio requiriese, bajo pena de privación del propio beneficio ${ }^{40}$. Su misión consistia en dar solemnidad a los actos litúrgicos y levantar las cargas de misas y otros encargos piadosos. Los beneficiados de preste estaban obligados a asistir en el confesionario y ayudar a los curas en la administración de la penitencia 41 , y todos los clérigos en general debian ayudar según su cargo ${ }^{42}$. Corrían tiempos de una gran religiosidad, por lo que abundaban las funciones de iglesia, y la solemnidad en el culto era algo habitual. Eran numerosos los encargos de misas, fundaciones a perpetuidad de memorias y vigilias, sin olvidar las obligaciones de los beneficiados por el propio beneficio, así como las bodas, entierros y todas las demás funciones religiosas que se desarrollaban en la parroquia 43 .

Formaban la comunidad eclesiástica y aunque cada uno vivía en su casa se reunían con frecuencia para tomar decisiones sobre nombramiento de cargos o las diferentes actividades que debían desarrollar. También se juntaban con ocasión de misas solemnes, vigilias, vísperas... Estas cargas se repartian con absoluta igualdad entre los beneficios y, si no todos percibian lo mismo en el reparto se debia a que no habían participado por igual en las actividades, bien por enfermedad o cualquier otra causa.

Respecto a la provisión de los cargos, como ha quedado expuesto unas líneas más arriba, en todos los casos había un predominio de la patrimonialidad local ya fuesen de libre presentación, patronato laico, o eclesiástico. Había beneficios en que el nombramiento de los cargos recaía en patronos laicos o eclesiásticos, aunque todos ellos entre «patrimoniales del pueblo». Los patronos laicos más destacados eran el marqués de Montealegre, que en Meneses de Campos -Arciprestazgo

40 MendozA, O. c., pp. 53-54.

41 Molino navarrete, J., o. c., pp. 48.

42 MENDOZA, o. $c$., "los clérigos de inferiores ordenes que estuviere en qualquiera de las yglesias parrochiales de nuestro Obispado, han de ayudar a los Curas, y ministrar y servirles cada uno en su officio, en la administracion de los santos Sacramentos, y el que no lo hiciere siendo desobediente, mandamos pierda la porcion de la offrenda y distribuciones quotidianas de aquel dia; y si permaneciere en su contumacia, incurra en pena de cien maravedis, la mitad para la fabrica de la yglesia, y la otra parte para obras pias; y si se atreviere el que asi fuera multado, o tomar la porción de la offrenda y distribuciones, incurra en pena de dos reales, aplicados a la mesma fabrica:.

43 Entre 1735 y 1744 en la iglesia de Frechilla se encargaron 12.560 misas rezadas, sin incluir las fundaciones, por lo que anualmente salía una media de 1.256. Herreros Estébanez, F., Historia de Frechilla, Ed. Diputación Provincial de Palencia, 1984, pp. 245. 
de Castromocho- nombraba siete beneficios; el marqués de la Mota, duque de Veragua que en la villa de Almaraz -Arciprestazgo de Urueñaproveía el curato. En Guaza -Arciprestazgo de Paredes de Nava- el curato le nombraba el duque de Abrantes, marqués de Aguilafuente ${ }^{44}$. Entre los patronos eclesiásticos habria que destacar en primer lugar al obispo de Palencia, que como Conde de Pernía nombraba curatos en diferentes Arciprestazgos del norte de la diócesis, concretamente en el de Bedoya y en algunos pueblos del de Cárdaño. Otros patronos eclesiásticos eran: el abad del Monasterio de San Zoilo, orden de San Benito, en Carrión de los Condes; la abadesa de San Andrés del Arroyo, orden de San Bernardo; el abad del Monasterio de San Isidro, orden de San Benito; el Abad de Sahagún -aunque perteneciente a la diócesis de León proveía algunos beneficios en la de Palencia-, los Capellanes del N. 940 -insertos en la Catedral-, o el propio Cabildo catedralicio que nombraba los cargos de las iglesias de la ciudad. Hay que destacar igualmente al abad de la abadía de Lebanza, que en el norte de la diócesis nombraba 6 curatos.

La mayoria de los Beneficios eran de libre presentación, mediante edictos públicos se convocaba a los naturales de las villas y lugares donde se producía la vacante, pudiendo concurrir todos aquellos que reuniesen los requisitos exigidos en la convocatoria, pues el nombramiento de los «Beneficios Presbiteriales, Curados, Diaconales, Subdiaconales y de Grados son debido en cualquier tiempo mes y forma que vaquen de los hijos legítimos Patrimoniales y Cualificados de cada una de las villas y lugares y sus respectivas iglesias, entre quienes se proveen sin que ahora ni en ningún tiempo se hayan imputado ni provisto por Su Santidad ni otra persona» 45 . El acceso a estos beneficios (que no eran de patronato), se hacia mediante concurso-oposición. En el momento de producirse la vacante, uno de los patrimoniales aspirantes al cargo, comunicaba al fiscal o provisor la vacante pidiendo que se difundiese la noticia mediante edicto público. Éste solía colocarse a la puerta de la iglesia, para que todos los que reuniesen los requisitos pudieran ejercer su derecho, desde ese momento se concedian quince días, improrrogables, para presentar las solicitudes.

44 El último nombramiento se realizó en 1927 en la persona de D. Pascual Escobar que regentó la parroquia hasta 1970. Herreros Estébanez, F., Historia de Guaza, o. c., pp.250. Este es el único caso que hemos encontrado sobre la provisión de los cargos no entre patrimoniales del pueblo, estaba establecido que el marqués debia nombrar para el puesto a un religioso del Convento de San Marcos de León, de la Orden Militar de Santiago.

45 «Expediente promovido a instancia del Sr. Fiscal (...) sobre la provisión de Beneficios de este Obispado. Año 1758 a 1808", A.H.N., Consejos, leg. 16.052. 
Pasado este tiempo, y según costumbre del tribunal, se acusaban dos "rebeldías de estilo" a los no comparecientes, y se presentaban las pruebas que atestiguasen reunir los requisitos exigidos en la convocatoria; es decir, poseer la patrimonialidad, tener la edad necesaria, los certificados acreditativos de haber realizado los estudios necesarios, y hallarse libre de todo impedimento canónico ${ }^{46}$. No se tenía en cuenta la vida y costumbres del opositor. Pasado este tiempo se señalaba día para el examen, que generalmente se hacía en casa del provisor a donde los examinadores acudían, y hacían juramento de evaluar únicamente los conocimientos 47 . EI examen constaba de varias partes: la primera correspondía a la prueba de gramática, elegida de forma conjunta por los examinadores y el provisor o fiscal. Ésta se comunicaba al opositor que, por sorteo entre ellos, le habia tocado participar en primer lugar, disponía de un cuarto de hora para prepararla. Pasado este tiempo la exponía ante el tribunal y «el que yerra quatro puntos enormes, en que se entiende error de caso, tiempo, adverbio, particula, adjetivo, sustantivo u otro que se siga notable variación en el sentido gramatical» quedaba suspendido y eliminado de la oposición ${ }^{48}$. Si el ejercicio no contenía errores graves, se le daba una "censura», es decir, una nota consistente en puntos enteros o medios, cuando el opositor sin destruir el sentido gramatical de la frase no le había dado el correcto. Esta «censura» no tenía una regulación fija ni estaba recogida en las sinodales, dependía del criterio de los examinadores. Superada esta prueba se pasaba a la segunda, consistente en un ejercicio de Teología, Cánones - Moral según los estudios que hubiese realizado el aspirante. Consistía en la lectura durante media hora de un texto, de entre tres que le dieron a elegir, y previa preparación de un cuarto de hora. A continuación uno de los examinadores le hacía una pregunta sobre el texto leido. Si concluía esta fase tenía aprobada la oposición ${ }^{49}$. El examen de los beneficiados de

46 MENDOzA, O. c., exigía que el aspirante reuniese los requisitns exigidos en la convocatoria en el momento de presentar las instancias, de lo contrario tendría que solucionarlo, pues aunque en el momento de realizar el examen hubiese solucionado el impedimento no se le permitiría participar de la oposición. La edad quedó fijada "para el beneficio de grados, aver entrado en catorze años, y para el beneficio de Epístola aver entrado en veynte y dos años, y para el de Evangelio en veynte y tres, y para el beneficio de preste, aver entrado en veynte y cinco, o tener asimesmo recurso,o estar ordenado o dispensado en algun defecto, que padezca".

47 MENDOZA, 0. c., pp. 159, limitó el número de examinadores a ocho y los honorarios de éstos a 12 rs., independientemente de la renta del beneficio o beneficios que se fuesen a cubrir. 48 «Expediente promovido a instancia del Sr. Fiscal (...) sobre la provisión de Beneficios Patrimoniales de este Obispado. Año 1758 a 1808», A.H.N., Consejos, leg. 16.052.

49 Molino Navartete, J., O. c., en el título XIII "De Beneficiis \& Beneficiatis pp. 54, suprimió el tercer examen de canto, entrando en vigor en 1769 la nueva normativa sobre el acceso a los beneficios patrimoniales. 
menores consistía en primer lugar en la prueba de gramática, y a continuación se le hacian preguntas relativas al orden correspondiente al beneficio al que aspiraban.

Superadas las pruebas se adjudicaba el beneficio al candidato más idóneo. Si se hallaban dos o más en la misma situación se les convoca a un segundo examen, adjudicando al que obtuviese mayor puntuación. Si lograban el mismo resultado se remitía al Prelado para que fuese éste el que eligiese al candidato que considerase más apto. En todo este proceso, ni los examinadores, ni el obispo tenían noticia de «las circunstancias, vida y costumbres del opositor", siendo una de las quejas que plantearon los obispos a la Cámara en el momento de elaborar los Planes de reforma. Este sistema de nombramiento de cargos ofrecia la ventaja de una mayor compenetración con los feligreses, pero también daba lugar a abusos y a una vocación dudosa, pues gran parte de ellos estarían más interesados en la obtención de unas rentas -por muy exiguas que fuesenque en el desempeño de sus funciones.

A continuación analizaremos el número de Beneficios que había por Arciprestazgos. Según un estudio realizado en 1768 la diócesis de $\mathrm{Pa}$ lencia contaba con 1.185 beneficios patrimoniales. En el siguiente cuadro quedan desglosados por categorías los que habia en cada Arciprestazgo 50.

50 «Expediente promovido a instancia del Sr. Fiscal (...) sobre la provisión de Beneficios Patrimoniales de este Obispado. Año 1758 a 1808» A.H.N., Consejos, leg. 16.052. 
DISTRIBUCIÓN DEL NÚMERO DE BENEFICIADOS POR ARCIPRESTAZGO

\begin{tabular}{|l|c|c|c|c|c|}
\hline ARCIPRESTAZGO & B.PRESTE & B.EVANGELIO & B.EPISTOLA & B.GRADOS & TOTAL \\
\hline ASTUDILLO & 45 & 7 & 6 & 8 & 66 \\
\hline AVIA DE LAS T. & 60 & 8 & 5 & 4 & 77 \\
\hline BALTANAS & 30 & 4 & 3 & 1 & 38 \\
\hline BECERRIL DE C. & 35 & 8 & 6 & - & 49 \\
\hline CARDAÑO & 1 & - & - & - & 1 \\
\hline CARRION DE LOS C. & 51 & 7 & 6 & 9 & 73 \\
\hline CASTREJON & 13 & 3 & 1 & 2 & 19 \\
\hline CASTROMOCHO & 40 & 11 & 8 & 7 & 66 \\
\hline CERBATOS DE LA C. & 31 & 1 & 8 & 2 & 4451 \\
\hline CEVICO DE LA T. & 59 & 2 & 1 & 5 & 67 \\
\hline DUEÑAS & 40 & 7 & 2 & 4 & 53 \\
\hline HERRERA & 48 & 2 & - & 9 & 59 \\
\hline OJEDA & 37 & - & - & 7 & 44 \\
\hline ORDEJON & 24 & 3 & - & 7 & 34 \\
\hline PAREDES DE NAVA & 60 & 19 & 18 & 10 & 107 \\
\hline PEÑAFIEL & 80 & 4 & 3 & 14 & 10452 \\
\hline POBACION DE C. & 99 & 10 & 9 & 6 & 124 \\
\hline POLACIONES & 6 & - & - & - & 6 \\
\hline RIOSECO & 19 & 9 & 8 & 9 & 49 \\
\hline TORDEHUMOS & 18 & 4 & 3 & 2 & 27 \\
\hline TORRELOBATON & 16 & 5 & 3 & 10 & 34 \\
\hline URUENA & 15 & 3 & 8 & 2 & 28 \\
\hline VICARIAS & 12 & 2 & 2 & - & 16 \\
\hline TOTAL & 839 & 118 & 101 & 122 & 1.185 \\
\hline
\end{tabular}

A la vista de estos datos lo primero que llama la atención era el elevado número de beneficios de preste frente a las demás categorías, representaban el $70,8 \%$ del total de beneficiados. La mayor concentración se producía en el centro y sur de la diócesis, siendo Población de Campos el Arciprestazgo que contaba con el mayor número, 99; seguido de Peñafiel con 80 y Paredes de Nava y Avia de las Torres con 60 cada uno. Conforme se avanza hacia el norte de la diócesis el número va disminuyendo, destacando los 37 del Arciprestazgo Ojeda o los 24 del de Ordejón, para

51 Hay dos beneficics en los que no se especificaba la clase.

52 En tres beneficios no detallaba la clase. 
llegar a los Arciprestazgos de la montaña con 6 en el de Polaciones y 1 en el de Cárdaño. En el sur de la diócesis había algunos Arciprestazgos con un reducido número de beneficiados, no era debido a una escasez de miembros, sino que estaban formados por un limitado número de pueblos, por ejemplo el Arciprestazgo de Rioseco lo integraban cuatro, y el de Tordehumos tres.

Respecto a las otras tres clases de beneficios observamos un comportamiento similar, de nuevo era el sur el que acaparaba el mayor número, y los Arciprestazgos que no contaban con todas las categorias beneficiales se localizaban en el norte, llegando al Arciprestazgo de Polaciones en el que no había ningún beneficio menor.

\subsection{Beneficios curados}

Eran los que llevaban aneja la cura de almas. Según Díaz Moreno, la cura animarum o cura de almas, en un sentido amplio, no sería otra cosa mas que la continuación en el tiempo y en el espacio de la misión salvadora de Cristo. En un sentido meramente descriptivo haría alusión a la "vigilancia y cuidado para evitar que las almas se pierdan, procurando su salvación mediante la instrucción, la corrección, y la administración de los sacramentos" 53 . En resumen la cura animarum era el deber, que tenian los curas o párrocos de atender espiritualmente a los feligreses. Era el oficio inherente a los curatos. Se ejercía normalmente de forma personal, bien por los titulares o por los tenientes de cura que actuaban subsidiariamente, también podia desarrollarse de forma solidaria (in solidum) por el cuerpo de beneficiados que ejercía alternativamente con arreglo a diferentes sistemas: mediante elección, colación, turno o sorteo. Para poder desempeñarlo era necesario haber recibido al menos la orden del presbiterado.

Era el máximo representante dentro de la parroquia y tenía la máxima responsabilidad. Debian desarrollar la triple misión del curato: sacerdotal (impartiendo los sacramentos), pastoral (mediante la dirección y vigilancia de los preceptos) y docente (enseñando la Doctrina Cristiana). Sus obligaciones eran precisamente el desempeño de estas funciones. Destacaba como prioritaria la administración de los sacramentos a los fie-

53 Diaz MORENO, J.M., La regulación jurídica de la cura de almas (en los canonistas hispánicos de los siglos XVI-XVII). Facultad de Teologia. Biblioteca Teológica Granadina. Granada.1972, pp. 43 y ss. 
les ${ }^{54}$. También debían visitar a los enfermos, administrando la Extremaunción a los que se hallaban en peligro de muerte, y como afirma M. Luisa Candau Chacón el cometido de los curas en el momento de la muerte era triple: mediante la administración de los Santos Óleos y la Extremaunción y el cuidado expreso de que testasen, señalando cómo la legislación eclesiástica primaba, en casos de gravedad el cuidado espiritual, llegando a prohibir expresamente las Sinodales la atención física al enfermo, si pasados tres días éste no había querido recibir los últimos sacramentos 55 .

Las tareas del curato incluian también la observancia en el cumplimiento de los preceptos y mandatos de la iglesia. Debian controlar la confesión y comunión anual, obligatoria en tiempos de Pascua de Resurrección, para ello elaboraban un padrón anual en el que anotaban si los feligreses habian cumplido o no con este precepto, imponiendo las penas espirituales, como la excomunión a los contraventores ${ }^{56}$. Debian vigilar igualmente la asistencia a la misa dominical o a las celebradas en los numerosos días festivos 57 . Además de verificar el cumplimiento de estas normas, también era tarea del curato la confección de ciertos libros sobre la administración de los sacramentos, como los de bautismo, en los que se anotaba el nombre de los padres y padrinos; o los de confirmación y matrimonio; sin olvidar los libros de partidas de difuntos, donde además de especificar los datos del fallecido el cura se hacía cargo de las mandas y legados, si estas habían sido estipuladas en el testamento.

Por último, como educadores de la fe predicaban la Divina Palabra y enseñaban la Doctrina Cristiana, ésta debía comprender los misterios de la fe, los mandamientos y las principales oraciones del cristiano. La explicación y su aprendizaje -obligatorio para los varones a partir de los catorce años y las hembras desde los doce-, se completaban con la enseñanza del Catecismo.

La posesión de un beneficio curado imponía el deber de residencia en el lugar donde estuviese constituido, este era un precepto impuesto desde Trento. El acceso se realizaba mediante oposición, y al respecto el sínodo de D. Álvaro de Mendoza estableció los conocimientos mínimos que

54 Mendoza, o. c., pp. 73, "Los Curas de las Yglesias Parrochiales deste nuestro Obispado, son obligados a administrar los santos Sacramentos de la yglesia, a sus Parrochianos".

55 Candau Chacon, M." L., o. c., pp. 104.

56 MendozA, A de, o. C, pp. 77-80.

57 Mendoza, A de, o.c, pp. 73. 
debían poseer los aspirantes a un beneficio curado 58 . El cura era el sacerdote encargado del cuidado, instrucción y pasto espiritual de una feligresía y estaba al frente de una parroquia considerada ésta como la reunión o conjunto de fieles confiados al cuidado espiritual de un párroco. Éste no podría atender a los feligreses de otra parroquia, a no ser que tuviese permiso de su párroco respectivo y cada feligrés debía saber a que parroquia pertenecía para acudir siempre a ella a recibir los sacramentos.

Respecto a los curatos palentinos el primer rasgo que debemos apuntar era el excesivo número de beneficiados, junto a la carencia casi absoluta de curas propios titulares de su empleo. La mayoría nombrados por patronos particulares, aunque entre patrimoniales del pueblo, entre los que podríamos destacar los 10 que nombraba el obispo, como conde de Pernía, en el Arciprestazgo de Bedoya y en numerosos pueblos del de Cárdaño. Los 6 designados por el abad de la Abadía de Lebanza, o los cuatro escogidos por el abad del Monasterio de San Zoilo.

Según una relación que en 1768 el obispo Loaces y Somoza remitió a la Cámara, para averiguar el número de cargos que había en la diócesis, así como la forma de proveerlos, podemos comprobar que los beneficios curados existentes se distribuian como sigue 59 :

DISTRIBUCIÓN DEL NÚMERO DE CURATOS POR ARCIPRESTAZGO

\begin{tabular}{|l|c|}
\hline ARCIPRESTAZGO & CUARTO \\
\hline BEDOYA & 5 \\
\hline CÁRDAÑO & 5 \\
\hline CARRIÓN DE LOS CONDES & 4 \\
\hline CASTREJÓN & 3 \\
\hline CASTROMOCHO & 1 \\
\hline CERBATOS DE CUEZA & 1 \\
\hline PAREDES DE NAVA & 2 \\
\hline POBLACIÓN DE CAMPOS & 1 \\
\hline TORDEHUMOS & 1 \\
\hline
\end{tabular}

58 MENDOZA, A de, o.c, 72-73, "a los quales (los examinadores) encargamos y mandamos, no la den (la licencia), ni aprueben al sacerdote que no tuviere bastante sufficiencia, assi en construir, como en la administracion de los santos Sacramentos, especial en el del baptismo, Eucharistia, y Penitencia, y casos de conciencia, y para dar la tal aprovacion, tengan assi mesmo attencion a la antigüedad, edad buena vida y costumbres, prudencia y mas sufficiencia".

59 «Expediente promovido a instancia del Sr. Fiscal (...) sobre la provisión de Beneficios Patrimoniales de este Obispado. Año 1758 a 1808", A.H.N., Consejos, leg. 16.052. 


\begin{tabular}{|l|c|}
\hline TORRELOBATÓN & 1 \\
\hline UREÑA & 1 \\
\hline TOTAL & 25 \\
\hline
\end{tabular}

No hay que olvidar que en la diócesis de Palencia el obispo era el cura titular de todas las parroquias, y ante la imposibilidad de poder desempeñarlo, nombraba "curas tenientes", que realizaban las funciones en su nombre. Eran cargos nutuales (amovibles) pudiendo ser nombrados y revocados a voluntad del otorgante, es decir, el prelado. Este cargo recaía en uno de los beneficiados de preste de la propia comunidad, verdaderos dueños tanto espirituales como materiales de la parroquia. La Reforma Beneficial tratará de corregir esta situación. 